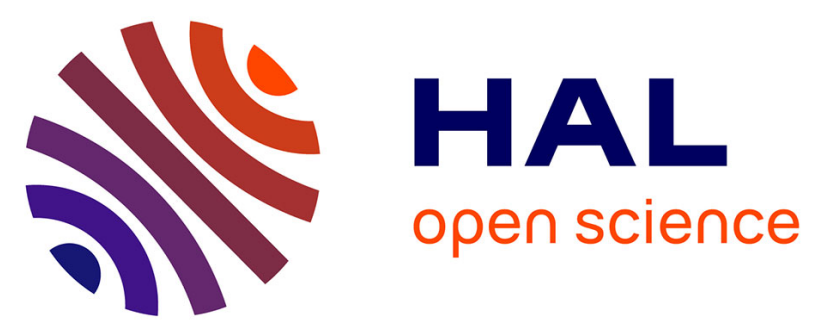

\title{
Experimental Analysis of the Vibroacoustic Response of an Electric Window-Lift Gear Motor Generated by the Contact Between Carbon Brushes and Commutator
}

S. Diop, Emmanuel Rigaud, P.-H. Cornuault, E. Grandais-Menant, B. Bazin

\section{- To cite this version:}

S. Diop, Emmanuel Rigaud, P.-H. Cornuault, E. Grandais-Menant, B. Bazin. Experimental Analysis of the Vibroacoustic Response of an Electric Window-Lift Gear Motor Generated by the Contact Between Carbon Brushes and Commutator. Journal of Vibration and Acoustics, 2017, 139 (6), pp.061002. 10.1115/1.4036869 . hal-02068275

\section{HAL Id: hal-02068275 \\ https://hal.science/hal-02068275}

Submitted on 15 Mar 2019

HAL is a multi-disciplinary open access archive for the deposit and dissemination of scientific research documents, whether they are published or not. The documents may come from teaching and research institutions in France or abroad, or from public or private research centers.
L'archive ouverte pluridisciplinaire $\mathbf{H A L}$, est destinée au dépôt et à la diffusion de documents scientifiques de niveau recherche, publiés ou non, émanant des établissements d'enseignement et de recherche français ou étrangers, des laboratoires publics ou privés. 


\section{Experimental analysis of the vibroacoustic response of an electric window-lift gear motor generated by the contact between carbon brushes and commutator}

S.Diop ${ }^{1}$

INTEVA Products, 14220 ESSON, France

Laboratoire de Tribologie et Dynamique des Systèmes, UMR CNRS 5513, Ecole

Centrale de Lyon, Université de Lyon, 36 avenue Guy de Collongue, 69134 ECULLY

cedex, France

SDIOP@intevaproducts.com

\section{E. Rigaud}

Laboratoire de Tribologie et Dynamique des Systèmes, UMR CNRS 5513, Ecole

Centrale de Lyon, Université de Lyon, 36 avenue Guy de Collongue, 69134 ECULLY

cedex, France

emmanuel.rigaud@ec-lyon.fr

\section{P-H. Cornuault}

Univ. Bourgogne Franche-Comté, FEMTO-ST Institute, CNRS/UFC/ENSMM/UTBM,

Department of Applied Mechanics, 25000 BESANÇON-FR, France

\footnotetext{
${ }^{1}$ Corresponding author.
} 
Journal of Vibration and Acoustics

pierre-henri.cornuault@ens2m.fr

\title{
E. Grandais-Menant
}

INTEVA Products, 14220 ESSON, France

EGrandaisMenant@intevaproducts.com

\section{B. Bazin}

INTEVA Products, 14220 ESSON, France

BBazin@intevaproducts.com

\begin{abstract}
This paper focuses on the experimental vibroacoustic behavior of an electric window-lift gear motor for automotive vehicle which consists of a DC motor and a worm gear. A specific test bench is designed. A standard configuration allows characterization of the levels and spectral contents of vibrations, acoustics and dynamic forces. The influence of operating speed, applied torque and mechanical imbalance is evaluated and the dispersion of results due to manufacturing, components assembly and operating temperature is highlighted. A modified configuration using an external drive allows the discrimination of some excitation sources associated to the contact between brushes and commutator by removing them one after the other. The respective weight of friction, mechanical shocks, electrical current flow and commutation arcs occurring jointly at the
\end{abstract}


brush/commutator interface are dissociated and evaluated. The friction and the mechanical shocks between brushes and commutator blades increase the vibroacoustic response of the window-lift gear motor. The flowing of electrical current in brushes/commutator contacts tends to moderate the frictional component of excitation sources while commutation arcs induce their rising, leading to a global additive contribution to the dynamic response.

Keywords: automotive vehicle, window-lift, DC motor, worm gear, experiments, vibroacoustic response, mechanical contacts, mechanical imbalance, brush/commutator contact, friction noise, mechanical shocks, electrical current flow, commutation arcs.

\section{INTRODUCTION}

Like other performances offered by an automotive vehicle such as safety, dynamics and fuel economy, the acoustic comfort within the passenger compartment has to be considered closely in the design process. During last decades, efforts have been continuously made to significantly reduce noise emission of powertrain [1]. Consequently, nuisance coming from the vehicle motorized accessories have now a significant impact on the noise perceived inside the automotive interior [2]. Among these, a gear motor equips each door of newer automotive vehicles in order to allow driver to go up and down the window. The window-lift gear motor is one of these peripheral organs which may annoy and disturb the driver when it is often used at vehicle stop [3]. 
The window-lift gear motor consists of a DC motor and a worm gear (cf. Fig. 1). The DC motor includes a fixed part consisting of steel and plastic housings (stator) and a rotational part (rotor). The stator supports the front, the center and the rear journal bearings guiding the rotor and the cage containing two metal-graphitic brushes which supply electrical power to the rotor. Diametrically opposed ferrites are also glued to the steel housing in order to induce a permanent magnetic field. The stator is attached to the door of the automotive vehicle at three fixation points. The rotor consists of a shaft on which coils are wound (number of coils: $\mathrm{N}=10$ ). Each coil is connected to one of the $\mathrm{N}$ blades of a rotating commutator. When the current flows in the coils positioned within the magnetic field, tangential (Lorentz) and radial (Maxwell) electromagnetic forces are created. The tangential forces induce the input torque which generates the rotating motion of the rotor. A worm is machined in the steel rotor, between the front and the center journal bearings. It meshes with a polyoxymethylene (POM) helical gear wheel in order to reduce the rotation speed and increase the motor output torque (number of gear teeth: $\mathrm{Z}=73$ ). The meshing generates a coupling between the axial and radial motions of the rotor due to the helix angle. Axial component of the force transmitted by the worm to the gear wheel is taken up by two curved pads acting as axial stops and mounted at each of the rotor ends. The worm gear is designed such as the meshing frequency $f_{m}$ is equal to the rotor frequency $f_{r}$ and the worm gear ratio is equal to 1:73. Finally, the gear wheel goes up and down the window depending on the direction of rotation of the window-lift motor, via a mechanical clutch connected to a drum and cables mechanism. The standard gear motor operation point corresponds to an input rotation speed equal to almost 7000 rpm and an output torque equal to 3 N.m. 
Under operating conditions, various mechanical and electromagnetic phenomena generate excitation of the window-lift gear motor. They induce vibration and noise radiated by the gear motor housing itself, as well as dynamical forces transmitted to the door which can also radiate inside the automotive interior. The following excitation sources are considered:

- At contacts between brushes and rotating commutator, (1) some mechanical shocks occur when brushes come into contact with the commutator blades, (2) the sliding contact between surfaces of the brushes and the commutator generates friction noise [4] and (3) commutation arcs occur when brushes lose contact with the blades [5].

- The fluctuation of the input electrical current at the contact between commutator and brushes and the periodic motion of the rotating coils through the permanent magnetic field generate periodic fluctuation of radial and tangential electromagnetic forces. Fluctuation of the radial forces directly excites the steel housing of the stator [6]. Fluctuation of tangential forces and the corresponding input torque is transmitted to the stator through the worm gear helical contact, the journal bearings and the axial pads.

- Shaft misalignment and mechanical imbalance induced by the asymmetry of the rotor are responsible for radial forces transmitted to the stator through the journal bearings and the axial pads $[7,8]$.

- The sliding contacts between worm and gear surfaces and between rotor/stator surfaces at the three journal bearings and the two axial pads generate friction noise [4]. 
- The meshing between the worm and the gear wheel is the source of an internal excitation corresponding to the static transmission error (STE) fluctuation. STE corresponds to the difference between the actual position of the driven gear and its theoretical one [9]. Its characteristics depend on the instantaneous locations of the meshing tooth pairs resulting from tooth deflections and manufacturing errors.

Furthermore, the gear mesh stiffness fluctuation associated with STE generates a parametric excitation of the mechanical system [10]. Under operating conditions, the internal excitation due to the meshing process is the origin of dynamic gear loads which are transmitted to the stator via the gear wheel body, the rotor, the journal bearings and the axial pads [10].

Some phenomena listed above correspond to broadband excitation, some occur every blade or coil passage $\left(10 f_{r}\right)$ and some others are periodic at the rotor frequency $f_{r}$ and at the mesh frequency $\left(f_{m}=f_{r}\right)$. The fundamental frequency associated with the different excitation sources are shown in Table 1.

\begin{tabular}{|l|l|}
\hline Excitation source & Frequency \\
\hline Mechanical shocks between brushes and commutator blades & $\mathrm{H} 10$ \\
\hline Commutation arcs & $\mathrm{H} 10$ \\
\hline Noise friction between brushes and commutator blades & Broadband \\
\hline Periodic fluctuation of the tangential electromagnetic forces & $\mathrm{H} 10$ \\
\hline Periodic fluctuation of the radial electromagnetic forces & $\mathrm{H} 10$ \\
\hline Shaft misalignment and mechanical imbalance & $\mathrm{H} 1$ \\
\hline Rotor/stator contacts at bearings and axial pads & Broadband \\
\hline Worm gear meshing & $\mathrm{H} 1+$ broadband \\
\hline
\end{tabular}


Seeking to differentiate and prioritize the different excitation sources of the window-lift gear motor, two complementary numerical and experimental approaches can be used.

For sources that can be modeled beforehand, their contribution to the vibroacoustic behavior can be evaluated from modeling of the gear motor dynamic response. For example, Dupont [11] proposed a simulation methodology to calculate the noise of an electrical motor generated by the radial (Maxwell) electromagnetic forces applied to the stator. First, time and space evolution of the radial magnetic forces is estimated using a 2D finite element model and an electromagnetic field simulation software. Excitation frequencies are associated with the number of magnetic poles and/or coils. Then, the excitation is projected onto the 3D stator structural finite element model in order to calculate its dynamic response. Hamzaoui et al. [12, 13] proposed to describe the vibraocoustic response of a rotor on bearings system taking account of several defects such as misalignment and imbalance. For this, a set of equivalent point sources is defined and placed on the structure surface to estimate the radiated noise. Excitation frequencies correspond to the rotor frequency and its harmonics. Concerning excitation sources generated by the meshing process, Tavakoli et al. [14] and Rigaud et al. [15] proposed a modeling of the gear teeth contact allowing evaluation of static transmission error and mesh stiffness periodic fluctuations. Main excitation frequencies correspond to the meshing frequency and its harmonics. The methodology was then extended to the worm gear mesh $[16,17]$. The resolution of the parametric equations of motion describing the system dynamic response then allows evaluation of the corresponding radiated whining noise [18]. Models of the overall dynamic response should also consider potential coupling between the different excitation sources. For this purpose, Dupont et al. [11] 
analyzed effect of static and dynamic rotor eccentricity on the radial magnetic excitation and the noise radiated by an automotive electric motor. Taking account of the dynamic eccentricity generated by misalignment leads to an enrichment of the excitation by additional components that combine the initial electromagnetic frequencies and the rotation frequency of the rotor.

Otherwise, different experimental approaches were also discussed in the literature. Cameron et al [19] developed a method to eliminate progressively sources in doubly salient variable-reluctance motors in order to identify the dominant noise source. Ben Abdelounis et al. [20] studied experimentally the roughness noise of dry rough flat sliding surfaces. Roughness noise is attributed to the multiples impacts between antagonist asperities of sliding surfaces. According to Akay [21], it depends on several parameters such as the geometry of the contact, the roughness of surfaces, the sliding speed, the normal load and the nature of materials.

This article presents an experimental approach for measuring the respective weight of some excitation sources of a window-lift gear motor, especially excitation sources linked to the contact between brushes and commutator that cannot be easily modeled. In particular, the weight of electrical commutation arcs, mechanical shocks and friction noise between brushes and commutator blades are studied in addition to the influence of operating speed, applied torque, mechanical imbalance and shaft misalignment. The first part describes the test bench which has been designed and used, as well as the protocol developed. Different test configurations are chosen to characterize the vibroacoustic behavior of the gear motor related to its external operating parameters, and to remove one after the other the different excitation sources that can be discriminated experimentally. 
The results obtained in the successive configurations are then compared to assess the relative weight of the studied excitation sources.

\section{EXPERIMENTAL APPARATUS AND MEASUREMENT PROTOCOL}

A test bench has been designed and built in order to analyze the vibroacoustic response of the window-lift gear motor. Experimental analysis of the different excitation sources is based on two configurations of the test bench (cf. Fig. 2): a standard configuration and a modified configuration which uses an external drive motor.

In standard configuration, the window-lift gear motor is mounted on a rigid and compact frame at the three points corresponding to its fixation points to the door of the automotive vehicle. An output shaft driven by the gear wheel is connected to a magnetic powder brake thanks to a flexible mechanical coupling. The kinematic chain is guided in rotation by rolling bearings. The powder brake applies the load which is usually required to translate the window. This one is measured using a torque meter. The output gear motor rotation speed is measured using a speed meter fixed to the end of the output shaft. The window-lift gear motor is energized using an electrical supply system. The test bench is controlled using a specific software. Tests are performed for an output torque equal to 3 N.m and different operating regimes which can be stationary (fixed speed) or variable (speed sweeps). In stationary operating condition, the test duration is $10 \mathrm{~s}$ and the input rotation speed is equal to $7000 \mathrm{rpm}$. In variable operating condition, the test duration is $60 \mathrm{~s}$ and the input rotation speed linearly increases from 0 to $7000 \mathrm{rpm}$ (or decreases from 7000 to $0 \mathrm{rpm}$ ). The input current is measured using a clamp meter. The temperature of 
the window-lift gear motor is measured using a thermocouple positioned at the surface of the steel housing. The vibroacoustic response of the window-lift gear motor is characterized using the following instrumentation. The vibratory response is measured using piezoelectric accelerometers glued on the plastic housing close to the brush/commutator contact, and on the steel housing. Sensitivity and weight are respectively $10.27 \mathrm{mV} / \mathrm{m} \cdot \mathrm{s}^{-2}$ and $4 \mathrm{~g}$. Acoustic response is measured using $1 / 4 \mathrm{in}$. microphones placed in the near-field, close to the brush/commutator contact at $6 \mathrm{~mm}$ of the gear motor, and in the far field at $70 \mathrm{~mm}$ of the gear motor. Sensitivity is $50 \mathrm{mV} / \mathrm{Pa}$. The normal and transversal forces at the fixation points are measured using two monoaxial and one triaxial piezoelectric force transducers. Time evolution of signals is recorded using a multi channels acquisition card. The sampling frequency is $44.1 \mathrm{kHz}$. The acoustic and vibratory references are respectively $2 \cdot 10^{-5} \mathrm{~Pa}$ and $1.10^{-6} \mathrm{~m} \cdot \mathrm{s}^{-2}$. Then, signals are post processed in order to analyze their power spectrum densities (PSD), and spectrograms which display the PSD time evolution during the speed sweeps. Finally, evolutions of specific tones and RMS values versus operating speed are deduced. The standard configuration allows characterization of the window-lift gear motor vibroacoustic response and analyzing effects of operating speed and applied torque. The effect of mechanical imbalance can also be analyzed using different conventional rotors.

A modified configuration which required an external drive motor is necessary to analyze the influence of electrical current flow, commutation arcs, mechanical shocks and friction noise between brushes and commutator blades on the window-lift gear motor vibratory response. In fact, these steps involve removing some components essential to the motor operation. To carry out this configuration, electromagnetic forces are removed by using 
steel housing with demagnetized magnets and the rotor is driven by an external brushless motor fixed to the rigid frame, via flexible mechanical couplings, belt and pulleys guided in rotation by rolling bearings. In this configuration, the rotating speed is limited to $4500 \mathrm{rpm}$.

\section{EXPERIMENTAL RESULTS AND DISCUSSION}

\subsection{Standard configuration}

The use of the test bench in standard configuration allows for characterizing the overall vibroacoustic behavior of the window-lift gear motor. The Figure 3 displays the evolution of the axial force transmitted at the fixation points in stationary operating condition at $7000 \mathrm{rpm}$. It shows a low frequency component at H1/73 having large amplitude and corresponding to the rotation frequency of the gear wheel. This component is associated with eccentricity and out-of-roundness defects of the gear wheel. It is not observable for the acceleration nor for the acoustic pressure responses because it is located out of the bandwidth of the sensors ( $\mathrm{f}<2 \mathrm{~Hz}$ ). The RMS value of the sum of the axial and radial forces transmitted at the fixation points is mainly due to this low frequency component. It is close to $11.5 \mathrm{~N}$ for axial forces and $7.5 \mathrm{~N}$ for radial forces. In the audible frequency range ( $\mathrm{f}>20 \mathrm{~Hz}$ ), the RMS value is close to $3.5 \mathrm{~N}$ for axial forces and $0.9 \mathrm{~N}$ for radial forces. 
The RMS value of the acceleration response measured in the vicinity of the brushes/commutator contacts is of the order of $7 \mathrm{~m} \cdot \mathrm{s}^{-2}$ that is $68 \mathrm{~dB}$. The sound pressure measured at $70 \mathrm{~mm}$ from the gear motor is of the order of $60 \mathrm{~dB}$.

The Figure 4 displays the power spectral density (PSD) of the acceleration response under stationary operating condition. The dynamic response shows many tonals corresponding to multiples of the rotation frequency which are superimposed on a broadband noise, especially between 0 and $6 \mathrm{kHz}$. In this frequency range, the RMS value is $67 \mathrm{~dB}$. The level of the dynamic response between $6 \mathrm{kHz}$ and $20 \mathrm{kHz}$ is lower and corresponds mainly to a broadband noise. In this frequency range, the RMS value is $55 \mathrm{~dB}$. The highest peaks emerging from the broadband noise level correspond to harmonics $\mathrm{H} 1, \mathrm{H} 10$ and $\mathrm{H} 20$. To determine the weight of the RMS value due to the tonals, the following methodology is applied. First, the RMS value of the overall acceleration signal $\left(\mathrm{RMS}_{\text {total }}\right)$ is calculated. Second, rectangular windows centred on the successive harmonics $\mathrm{H}_{\mathrm{i}}$ of the rotation frequency are applied in order to identify the tonal part of the total signal. For each harmonic $H_{i}$, the frequency range $(\Delta f)$ is defined as follows:

$\Delta \mathrm{f}=\left[\mathrm{f}_{\mathrm{i}}-3 \cdot \log _{10}\left(\mathrm{f}_{\mathrm{i}}\right) ; \mathrm{f}_{\mathrm{i}}+3 \cdot \log _{10}\left(\mathrm{f}_{\mathrm{i}}\right)\right]$

The broadband noise part is defined as the signal energy recorded out of these intervals. Finally, the tonals proportion of the signal (TP) is defined as follows:

$$
\mathrm{TP}=\mathrm{RMS}_{\text {tonal }}{ }^{2} / \mathrm{RMS}_{\text {total }}{ }^{2} \text { (with } \mathrm{RMS}_{\text {total }^{2}}=\mathrm{RMS}_{\text {tonal }}{ }^{2}+\mathrm{RMS}_{\text {broadband }^{2}} \text { ) }
$$


At 3 N.m and 7000 rpm, tests performed with 5 different window-lift gear motors show that $\mathrm{TP}=82.7 \pm 2.8 \%$ in the frequency range $[0-6 \mathrm{kHz}]$.

The Figure 5 displays the spectrogram of the acceleration response for a speed sweep ranging from 0 to $7000 \mathrm{rpm}$. It highlights emergence of the $\mathrm{H} 1, \mathrm{H} 10$ and $\mathrm{H} 20$ harmonics. Two modal amplification areas are also observed around $1 \mathrm{kHz}$ and $2.2 \mathrm{kHz}$.

The Figure 6 displays the RMS value of the acceleration response versus the rotation speed of the rotor. Stars appearing in the figure are mean values obtained with 5 windowlift gear motors and the height of error bars corresponds to the standard deviation. This figure mainly highlights the increase of the RMS value of the gear motor vibratory response with the torque ( $+5 \mathrm{~dB}$ when applying $3 \mathrm{~N} . \mathrm{m})$ and with the input rotation speed of the gear motor (+4.9 dB/octave). Moreover, a significant dispersion of the gear motor vibratory response is observed. Among all the reasons which could explain this dispersion, we can note the difference in production and assembly of the gear motor components, particularly the gear wheel manufacturing errors and the assembly between plastic and steel housings, or/and the misalignment between the rotor shaft and the bearings. Another reason explaining the dispersion is temperature variation between tests. It must be noticed that tests duration $(60 \mathrm{~s})$ were greater than the usual operating duration of the window-lift gear motor (approximately $4 \mathrm{~s}$ ). Hence, temperature rose more than usual leading to modifications of the acceleration response due to various physical phenomena such as parts expansion, changes in the loads transmission, frictional behavior modification, etc. Indeed, preliminary tests performed with the same rotor at different temperatures (measured on the steel housing) comprised between 23 and $39^{\circ} \mathrm{C}$ have shown a linear increase of $0.46 \mathrm{~dB} /{ }^{\circ} \mathrm{C}$ of the acceleration $\mathrm{RMS}$ value at $4500 \mathrm{rpm}$. 
Another series of tests was performed with a set of five rotors having various mechanical imbalances: for this, the rotor armature stack has been intentionally machined in order obtain mechanical imbalances in a range larger than usual (from 0 to 1.6 g.mm). The Figure 7 displays the RMS value of the overall acceleration response $\left(\mathrm{RMS}_{\text {total }}\right)$ and the RMS value of $\mathrm{H} 1$ versus mechanical imbalances of the rotor. The RMS value of H1 was determined following the method mentioned above for the calculation of $\mathrm{RMS}_{\text {tonal }}$ but taking only into account the first tonal. As suggested above (cf. Table 1), the RMS value of $\mathrm{H} 1$ linearly increases with the rotor mechanical imbalance. Nevertheless, $\mathrm{RMS}_{\text {total }}$ does not show such a correlation. Indeed, the RMS value of $\mathrm{H} 1$ represents only $11 \pm 5 \%$ of $\mathrm{RMS}_{\text {total }}$ depending on the mechanical imbalance considered. Therefore, $\mathrm{RMS}_{\text {total }}$ is not highly affected by fluctuation of the rotor mechanical imbalance.

\subsection{Modified configuration: excitation sources discrimination}

The modified configuration of the test bench was used to assess the relative weight of the excitation sources involved in the operation of the two brushes/commutator contacts. As mentioned above, friction, mechanical shocks, electrical current flow and commutation arcs occur jointly at the brush/commutator interface, the three followings rotors are used in order to dissociate the effect of these excitation sources.

Rotor 1: the commutator is intentionally not segmented. This affects the brushes/commutator interaction by avoiding the mechanical shocks which usually occur when a brush rubs from a commutator blade to the following one. Moreover, coils are 
also electrically short-circuited, resulting in the lack of commutation arcs when electrical current flows through the brush/commutator contact.

Rotor 2: the commutator remains segmented but the electrical connections between coils and commutator blades are cut off. All blades have been connected together with a copper wire which has been soldered at each blade ending in order to allow electrical current flowing from one brush to the second one through the commutator. Consequently, commutation arcs do not occur due to coils short-circuiting.

Rotor 3: the rotor is unchanged compared to the rotor used in a classical window-lift gear motor.

For each rotor, brushes can rub on the commutator or can be removed. In the case of brushes rubbing on the commutator, electrical current can be injected or not. The use of the 3 rotors combined with the existence (or not) of brushes and electrical current flow involves various test conditions for which friction, mechanical shocks, electrical current flow and commutation arcs could be independently applied or removed. The Table 2 lists the testing conditions which were used for the trials named A to G.

\begin{tabular}{|c|c|c|c|c|c|c|c|c|c|c|}
\hline \multirow{2}{*}{ Rotor } & \multirow{2}{*}{ Trial } & \multirow{2}{*}{ Brushes } & \multirow{2}{*}{$\begin{array}{l}\text { Current } \\
\text { flow }\end{array}$} & \multicolumn{4}{|c|}{ Excitation sources involved } & \multirow{2}{*}{$\begin{array}{c}\ddot{x} \\
\text { RMS }\end{array}$} & \multirow{2}{*}{$\begin{array}{l}\ddot{x}_{d B} \\
\text { RMS }\end{array}$} & \multirow{2}{*}{$\begin{array}{l}\Delta \ddot{x}_{d B} \\
\text { RMS }\end{array}$} \\
\hline & & & & Friction & Shocks & Current & Arcs & & & \\
\hline \multirow[t]{2}{*}{1} & A & no & no & & & & & 2.11 & 63.25 & - \\
\hline & B & yes & no & $\oplus$ & & & & 2.57 & 64.10 & 0.85 \\
\hline \multirow{3}{*}{2} & $\mathrm{C}$ & no & no & & & & & 1.51 & 61.80 & - \\
\hline & $\mathrm{D}$ & yes & no & $\oplus$ & $\oplus$ & & & 2.26 & 63.55 & 1.75 \\
\hline & E & yes & yes & $\oplus$ & $\oplus$ & $\oplus$ & & 1.95 & 62.90 & 1.10 \\
\hline
\end{tabular}




\begin{tabular}{|c|c|c|c|c|c|c|c|c|c|c|}
\hline 3 & $\mathrm{~F}$ & no & no & & & & & 2.19 & 63.40 & - \\
\cline { 2 - 10 } & $\mathrm{G}$ & yes & yes & $\oplus$ & $\oplus$ & $\oplus$ & $\oplus$ & 3.63 & 65.60 & 2.20 \\
\hline
\end{tabular}

Five tests were performed for each trial with a rotation speed sweep ranging from 0 to $4500 \mathrm{rpm}$. Every trial leads to plot the evolution of the mean RMS value of the acceleration response versus the rotation speed of the rotor resulting in a curve similar to the one displayed in Fig. 5. Assuming a linear increase of the RMS value (in $\mathrm{dB}$ ) versus the rotor rotation speed (plotted on a logarithmic to the base 2 scale), a linear approximation has been plotted for each trial. The mean slope of these approximations is $3.7 \pm 1.0 \mathrm{~dB} /$ octave, corresponding in a value close to that found with the standard configuration that is, in absence of the external drive motor. The RMS values of the linear approximations at $4500 \mathrm{rpm}$ for each trial have been collected and are reported in Table 2.

The results interpretation methodology has to take account for gear motor vibroacoustic response dispersion related to rotors design even if the difference of shape and mass between the three rotors is weak. Indeed, the standard deviation of the acceleration RMS values for trials $\mathrm{A}, \mathrm{C}$ and $\mathrm{F}$ is $\pm 0.9 \mathrm{~dB}$ whereas test conditions are the same, apart from the use of three different rotors. Consequently, the effect of the four excitation sources on the vibroacoustic behavior is quantified with respect to a reference setup. This one corresponds to the trials $\mathrm{A}, \mathrm{C}$ and $\mathrm{F}$. It means the reference vibroacoustic response is not the response observed in standard configuration, but is defined in modified configuration and in the absence of brushes. The cumulative effects of the four excitation sources are then considered by comparison of two trials for which the same rotor has been used. 
The comparison between trials A and B shows an increase of $0.85 \mathrm{~dB}$ of the acceleration RMS value. As expected, this means that the addition of the brushes/commutator friction with respect to the reference setup increases the vibroacoustic response of the window-lift gear motor. The comparison of trials $\mathrm{C}$ and $\mathrm{D}$ shows an increase of $1.75 \mathrm{~dB}$ of the acceleration RMS value with respect to the reference setup. Thus, the mechanical shocks of brushes on the commutator blades edge involve an additional increase of the acceleration RMS value compared with the increase due to friction only. The comparison of trials $\mathrm{C}$ and $\mathrm{E}$ shows an increase of $1.1 \mathrm{~dB}$ when friction, mechanical shocks and electrical current flowing occur simultaneously at the brushes/commutator interfaces, with respect to the reference setup. An important feature of this result is the least increasing of the window-lift gear motor vibroacoustic response when electrical current flows through the contacts than without current $(+1.1 \mathrm{~dB}$ against $+1.75 \mathrm{~dB})$. This result can be explained by the so-called "electro-lubrication" mechanism [22] which was first observed by Lancaster [23]. The friction force decrease with electrical current has been extensively observed [24-27] and explained by the modification of graphitic platelets orientation on brushes surfaces due to electrostatic stress [23]. Zaidi et al. [27] carried out experiments with very similar testing conditions than those encountered in this paper in terms of normal load, speed, materials, etc. They measured a decrease of approximately $30 \%$ of the friction coefficient when current flows through the contact. The flowing of electrical current in brushes/commutator contacts of the gear motor studied tends thus to moderate friction forces, resulting in the lowering of the excitation due to friction. The comparison of trials $\mathrm{F}$ and $\mathrm{G}$ shows a large increase of $+2.2 \mathrm{~dB}$ of the RMS value when commutation occurs in addition to the three earlier excitation sources. Compared to the 
other trials, trial G highlights the major role played by commutation in the vibroacoustic behavior of the brushes/commutator system. Commutation phenomenon is usually associated to the presence of arcing and sparking at the brush/commutator contact [5]. These electrical discharges generate wear [28-30] which modifies the brushes and commutator surfaces topography and roughness and then induces an increase of friction forces $[22,31,32]$. In the present study, surface damages owed by commutation arcs induce the rising of the frictional component of excitation sources.

Finally, the acceleration response of the gear motor appears to be highly influenced by both friction and shocks occurring between the brushes and the commutator. In the case of friction, commutation phenomenon tends to largely increase the acceleration response whereas electrical current flow leads to lowering it. Furthermore, similar trends are observed concerning the acoustical response measured with the near-field microphone that is: $+0.3 \mathrm{~dB}$ (compared with the reference setup) when only friction and shocks occur, $+0.2 \mathrm{~dB}$ with the addition of electrical current, and $+1.1 \mathrm{~dB}$ when commutation is added.

\section{CONCLUSION}

The experimental vibroacoustic behavior of an electric window-lift gear motor for automotive vehicle which consists of a DC motor and a worm gear has been analyzed. For this, a specific test bench has been designed. Through a standard configuration, the levels and spectral contents of vibrations, acoustics and dynamic forces have been characterized. Main tonals correspond to harmonics of $\mathrm{H} 1$ and $\mathrm{H} 10$ and can be related respectively to worm gear meshing, shaft misalignment and mechanical imbalance, and 
to periodic fluctuation of the electromagnetic forces, commutation arcs and mechanical shocks between brushes and commutator blades. Dynamic forces at the fixation points are also characterized by a low frequency component associated with the gear wheel rotation frequency. The influences of operating speed (+4.9 dB/octave), applied torque (+5 dB) mechanical imbalance have been evaluated and the dispersion of results due to manufacturing uncertainties, components assembly which generates misalignment between the rotor and bearings and operating temperature $\left(+0.46 \mathrm{~dB} /{ }^{\circ} \mathrm{C}\right)$ has been highlighted.

Through a modified configuration using an external drive, some excitation sources associated to the contact between brushes and commutator have been discriminated by removing them one after the other. The respective weight of friction, mechanical shocks, electrical current flow and commutation arcs occurring jointly at the brush/commutator interface have been evaluated by overcoming the dispersion due the components assembly and the design of different rotors used. The friction alone and the mechanical shocks between brushes and commutator blades increase the vibroacoustic response of the window-lift gear motor. The flowing of electrical current in brushes/commutator contacts tends to moderate component of excitation sources while commutation arcs induce their rising, leading to a global additive contribution to the dynamic response.

\section{ACKNOWLEDGMENTS}

The authors wish to thank M. Guibert, S. Zara, T. Durand and L. Charles for their contribution to the experimental apparatus development. 
Journal of Vibration and Acoustics

\section{NOMENCLATURE}

$f_{m} \quad$ Meshing frequency

$f_{r} \quad$ Rotor frequency

H1 First harmonic corresponding to the rotor frequency

H10 Tenth harmonic corresponding to ten times the first harmonic

H20 Twentieth harmonic corresponding to twenty times the first harmonic

$N \quad$ Number of coils

$\mathrm{RMS}_{\text {broadband }} \mathrm{RMS}$ value of the broadband noise

$\mathrm{RMS}_{\text {tonal }} \quad \mathrm{RMS}$ value of tonals

$\mathrm{RMS}_{\text {total }} \quad \mathrm{RMS}$ value of the overall signal

$Z \quad$ Number of gear teeth 


\section{REFERENCES}

[1] Qatu, M.S., Abdelhamid, M.K., Pang, J., Sheng, G., 2009, “Overview of automotive noise and vibration," International Journal of Vehicle Noise and Vibration, 5, Issue 1-2, pp. 1-35. Doi: 10.1504/IJVNV.2009.029187.

[2] Robinson, I., Walsh, S.J., and Stimpson, G., 1998, "Vehicle accessory tonal noise: experimental determination and subjective assessment," Proceedings of the International Congress on Noise Control Engineering, Christchurch, New Zealand, November 16-18, 1998, Sound and silence, setting the balance, Auckland, N.Z. New Zealand Acoustical Society, pp. 1049-1052.

[3] Revel, GM., Santolhi, C., Tomasini, E.P., 1997, "Laser-dopler vibration and acoustic intensity measurements for dynamic characterization and noise reduction in a car window lift system," Proceedings of the 15th International Modal Analysis Conference, SPIE Vol. 3089, p. 1636.

[4] Le Bot, A., Bou Chakra, E., 2010, "Measurement of Friction Noise Versus Contact Area of Rough Surfaces Weakly Loaded,” Tribology Letters, 37, Issue 2, pp. 273-281.

[5] Holm, R., "Electric contacts - Theory and application," 1967, Springer-Verlag, Berlin.

[6] Hallal, J., Druesne, F., Lanfranchi, V., 2013, “Study of electromagnetic forces computation methods for machine vibration estimation," ISEF Conference.

[7] Xut, M., Marangoni, R.D., 1993, "Vibration analysis of a motor-flexible couplingrotor system subject to misalignment and unbalance. Part 1: Theoritical model analysis," Journal of sound and vibration. 
[8] Xut, M., Marangoni, R.D., 1993, "Vibration analysis of a motor-flexible couplingrotor system subject to misalignment and unbalance. Part 2: Experimental validation," Journal of sound and vibration.

[9] Welbourn, D.B., 1979, "Fundamental Knowledge of Gear Noise - A Survey," Conference on Noise and Vibrations of Engines and Transmissions. Cranfield Institute of Technology, Paper C177/79, pp. 9-29.

[10] Rigaud, E., Sabot, J., Perret-Liaudet, J., 2000, “Comprehensive approach for the vibrational response analysis of a gearbox,” Revue européenne des éléments finis, 9, Issue 1-3, pp. 315-330.

[11] Dupont, J.B., Aydoun, R., Bouvet, P., 2014, "Simulation of the Noise Radiated by an Automotive Electric Motor: Influence of the Motor Defects," SAE International Journal of Alternative Powertrains, 3 issue 2, pp. 310-320, doi: 10.4271/2014.01.2070.

[12] Hamzaoui, N., Boisson, C., Lesueur, C., 1998, "Vibroacoustic analysis and identification of defects in rotating machinery, part I, theoretical model," Journal of sound and vibration $216(4)$, pp. 553-570.

[13] Hamzaoui, N., Boisson, C., Lesueur, C., 1998, "Vibroacoustic analysis and identification of defects in rotating machinery, part II, experimental study," Journal of sound and vibration $216(4)$, pp. 571-583.

[14] Tavakoli, M.S., Houser, D.R., 1986, “Optimum Profile Modifications for the Minimization of Static Transmission Errors of Spur Gears,” J. Mech. Trans. and Automation 108(1), pp. 86 -94. 
[15] Rigaud, E., Barday, D., 1999, "Modelling and analysis of static transmission error. Effect of wheel body deformation and interactions between adjacent loaded teeth," 4th World Congress on Gearing and Power Transmission, Paris, pp. 1961-1972.

[16] Hiltcher, Y., Guingand, M., De Vaujany, J.P., 2006, "Load sharing of worm gear with a plastic wheel,” J. Mech. Des. 129(1), pp. 23-30, doi:10.1115/1.2359469.

[17] Jbily, D., Guingand, M., De Vaujany, J.P., 2014, "Loaded behaviour of steel/bronze worm gear," proceedings of the International Gear Conference, Lyon, pp. 32-42.

[18] Carbonelli, A., Rigaud, E., Perret-Liaudet, J., 2016, “Vibro-Acoustic Analysis of Geared Systems - Predicting and Controlling the Whining Noise," Automotive NVH Technology, Editors Fuchs A., Nijman E., Priebsch H-H., Springer Briefs in Applied Sciences and Technology, Springer International Publishing, pp. 63-79, ISBN 978.3.319.24055.8.

[19] Cameron, D.E., Lang, J.H., 1992, “The origin and reduction of acoustic noise in doubly salient variable-reluctance motors," IEEE Transactions on industry applications, vol.28, no 6 .

[20] Ben Abdelounis, H., Le Bot, A., Perret-Liaudet, J., Zahouani, H., 2010, “An experimental study on roughness noise of dry rough flat surfaces," Wear, 268, 4 issues 12, pp. 335-345.

[21] Akay, A., 2002, “Acoustics of friction,” J. Acoust. Soc. Am. 111, pp. 1525-1548. 
[22] Braunovic, M., Konchitz, V.V., Myskkin, N.K., 2007, "Electrical Contacts Fundamentals Application \& Technology,” CRC Press ed., London, NY.

[23] Lancaster, J.K., 1964, "The effect of current on the friction of carbon brush materials," British Journal of Applied Physics, Vol. 15, pp. 29-43.

[24] Paulmier, D., EL Mansori, M., Zaidi, H., 1997, “Study of magnetized or electrical sliding contact of a steel XC48/graphite couple,” Wear, Vol. 203-204, pp. 148-154.

[25] Zhao, H., Barber, G.C., Liu, J., 2001, "Friction and wear in high speed sliding with and without electrical current," Wear, Vol. 248, pp. 409-414.

[26] Robert, F., Csapo, E., Zaidi, H., Paulmier, D., 1995, “Influence of the current and environment on the superficial structure of a graphite electrical collector," International Journal of Machine Tools \& Manufacture, Vol. 35 (2), pp. 259-262.

[27] Csapo, E., Zaidi, H., Paulmier, D., Kadiri, E.K., Bouchoucha, A., Robert, F., 1995, "Influence of the electrical current on the graphite surface in an electrical sliding contact," Surface and Coatings Technology, Vol. 76-77, pp. 421-424.

[28] Hamilton, R.J., 2000, “DC motor brush life”, IEEE Transactions on industry applications, Vol. 36 (6), pp. 1682-1687.

[29] Lawson, D.K., Dow, T.A., 1985, “The sparking and wear of high current density electrical current,” Wear, Vol. 102, pp. 105-125. 
[30] Sawa, K., Shimoda, N., 1992, “A study of commutation arcs of DC motors for automotive fuel-pumps," IEEE Transactions on components, hybrids and manufacturing technology, Vol. 15 (2), pp. 193-197.

[31] Shobert, E.I., 1965, “Carbon brushes - The physics and chemistry of sliding contact," Chemical Publishing Company ed., NY.

[32] Takaoka, M., Sawa, K., 2001, “An influence of commutation arcs in gasoline on brush wear and commutator," IEEE Transactions on components and packaging technologies, Vol. 24 (3), pp. 349-352. 


\section{Figure Captions List}

Fig. 1 Window-lift gear motor. Steel (1) and plastic housings (11) - permanent magnet (2) - carbon brushes (6) - rear (4), center (7) and front bearings (9) - fixation points (12) - coils (3) - commutator (5) - worm (8) - gear wheel (10).

Fig. 2 Experimental test bench. Speed meter (1) - Torque meter (2) - Powder brake (3) - Flexible mechanical couplings (4) - Window-lift gear motor (5) - External brushless motor (6).

Fig. 3 Axial force time evolution signal at $7000 \mathrm{rpm}$ when applying a 3 N.m torque.

Fig. 4 Power spectrum density (PSD) of the gear motor vibratory response at 7000 rpm when applying a 3 N.m torque.

Fig. 5 Spectrogram of the gear motor vibratory response when gear motor input velocity varies from 0 to $7000 \mathrm{rpm}$ and applying a 3 N.m torque.

Fig. 6 Evolution of the gear motor vibratory response according to the gear motor input velocity and the torque applied.

Fig. 7 Effect of the mechanical imbalance on the gear motor vibratory response at $7000 \mathrm{rpm}$. Red rounds correspond to RMS values of the overall acceleration signal and blue crosses correspond to H1 RMS values. 


\section{Table Captions List}

Table $1 \quad$ Frequencies associated to each excitation source

Table 2 Test conditions of the trials A to G, excitation sources involved, and corresponding acceleration RMS values at $4500 \mathrm{rpm} . \ddot{x}$ is the acceleration,

$\ddot{x}_{d B}$ is the value in $\mathrm{dB}$ (with reference $1.10^{-6} \mathrm{~m} / \mathrm{s}^{2}$ ), and $\Delta \ddot{x}_{d B}$ is the difference in $\mathrm{dB}$ relative to the reference trial (performed with the same rotor). 
Journal of Vibration and Acoustics

Fig. 1:

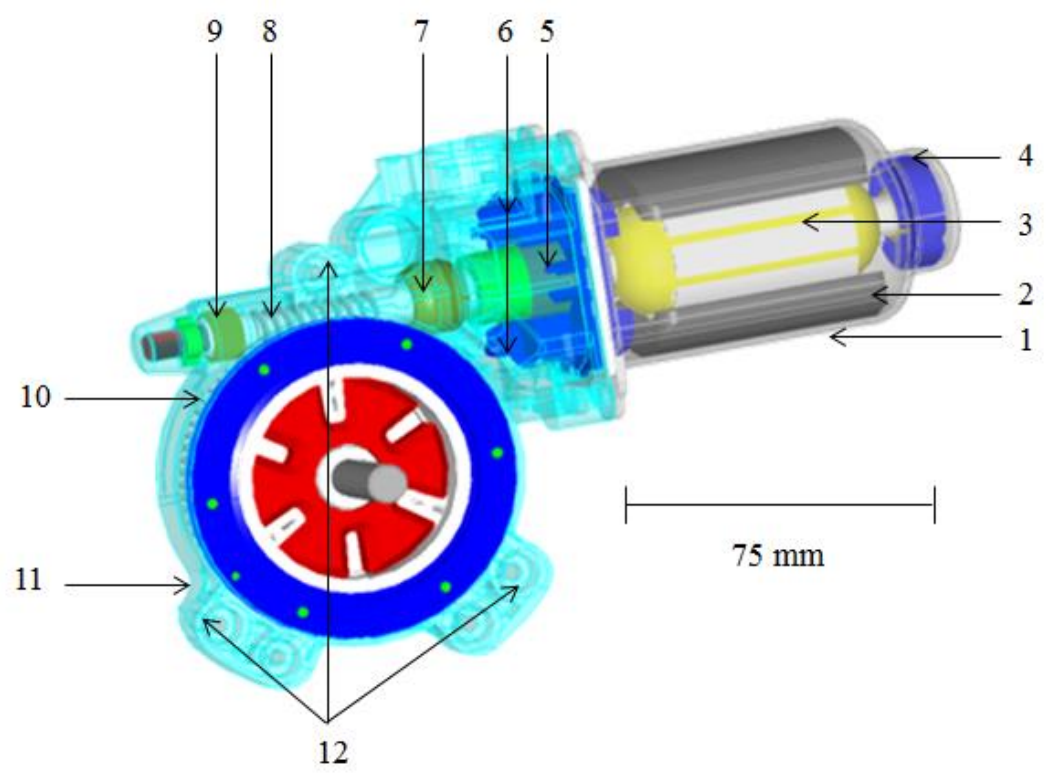


Fig. 2:

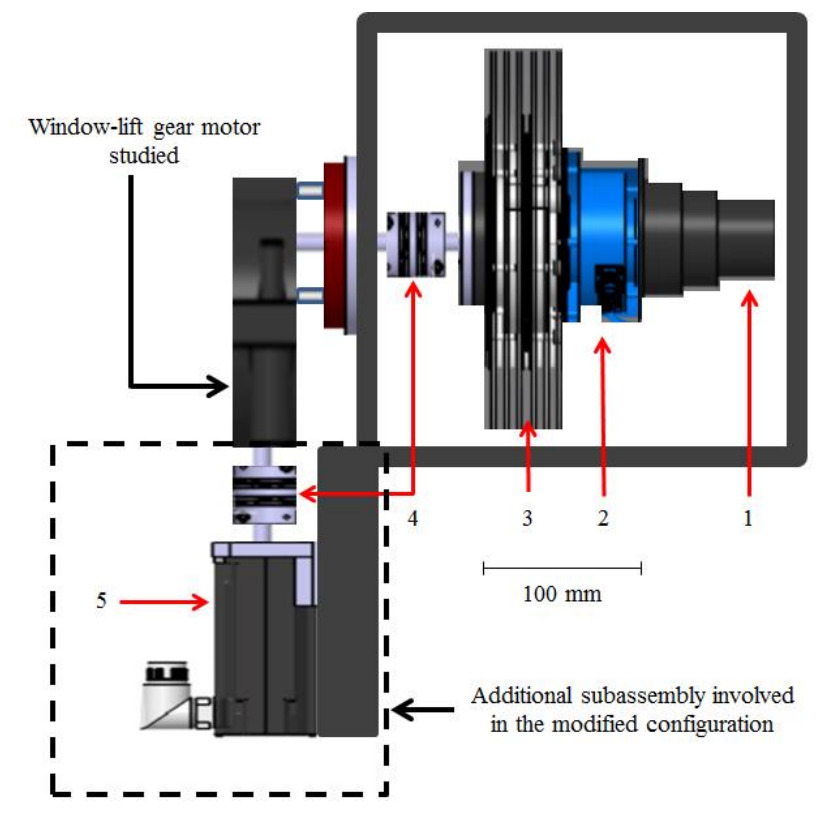


Journal of Vibration and Acoustics

Fig. 3:

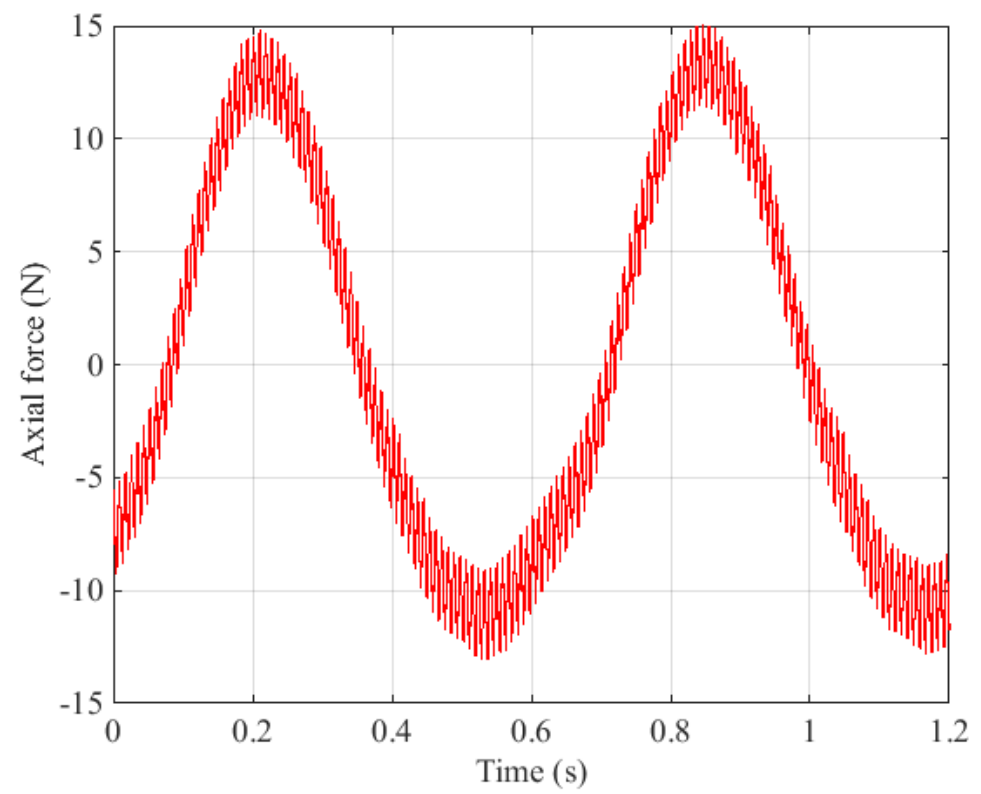


Journal of Vibration and Acoustics

Fig. 4:

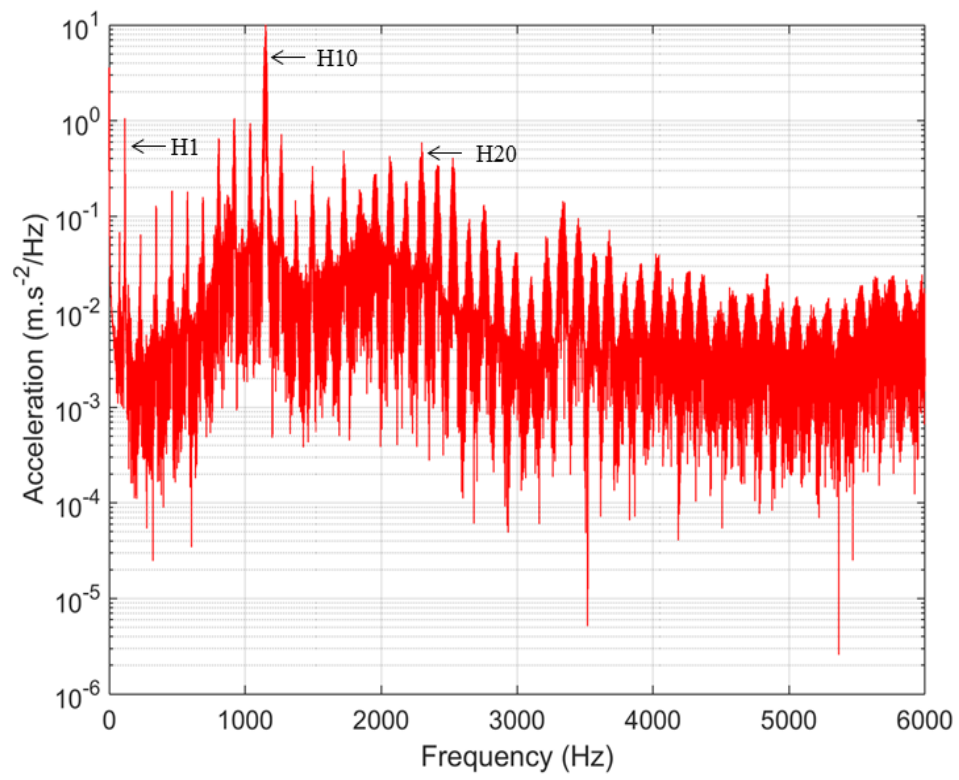


Journal of Vibration and Acoustics

Fig. 5:

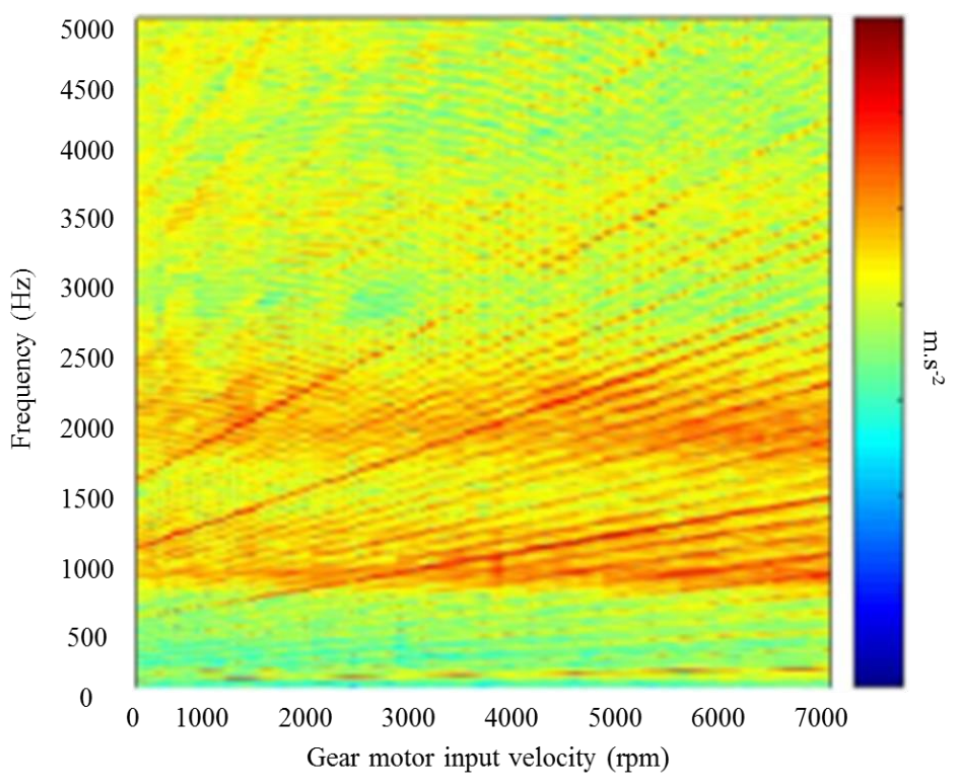


Journal of Vibration and Acoustics

Fig. 6:

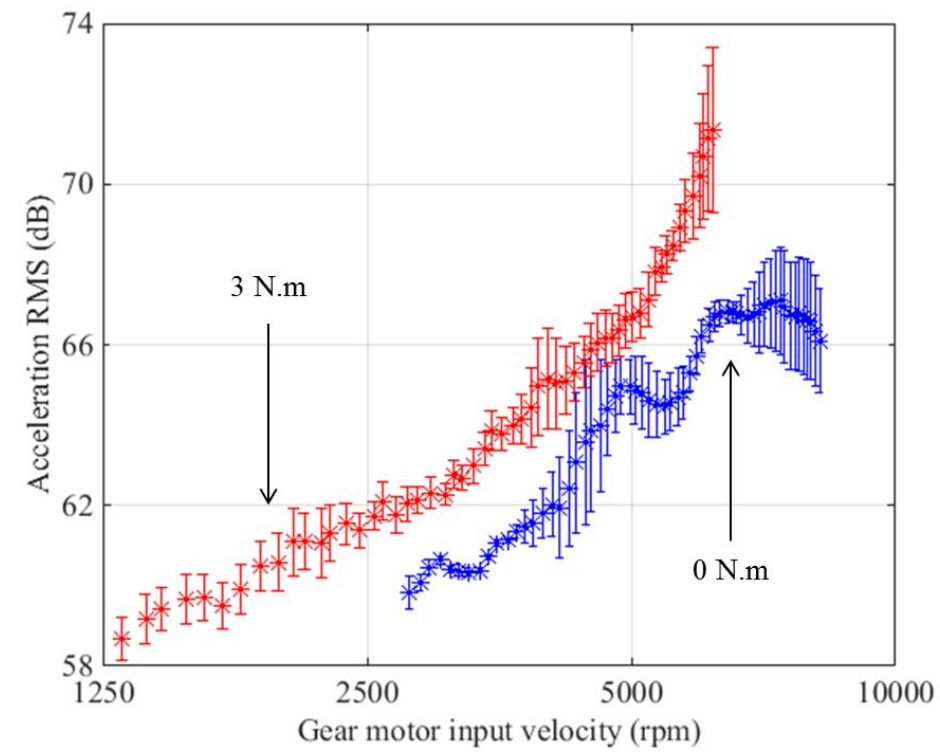


Journal of Vibration and Acoustics

Fig. 7:

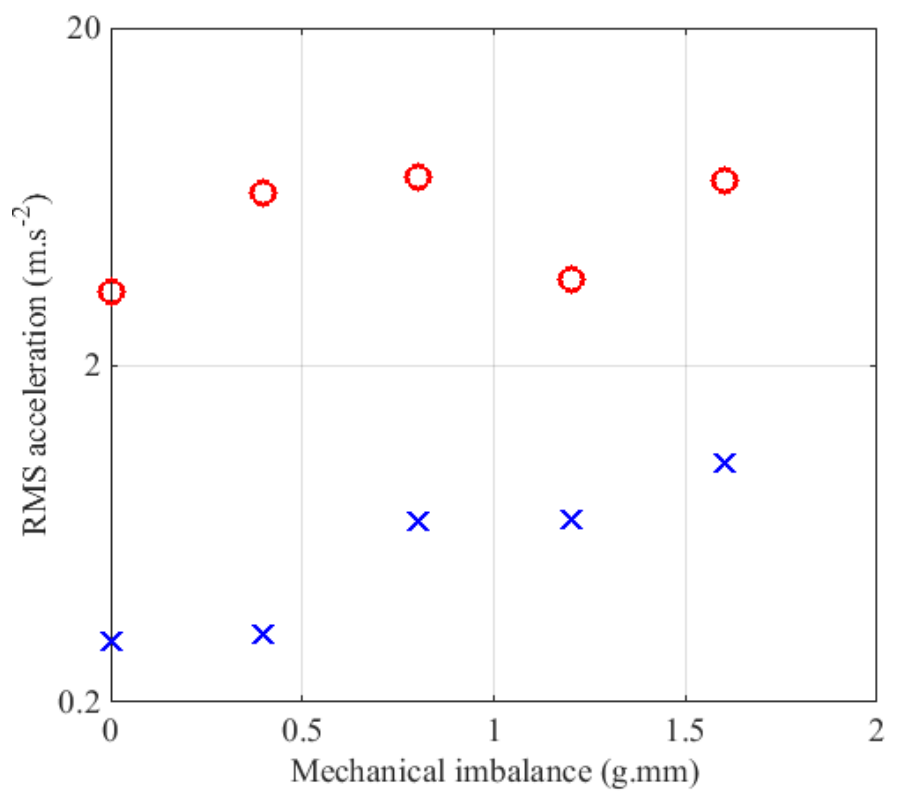

